\title{
Implicações do Sinaes na gestão da educação superior: análise micropolítica
}

\author{
Implications of the Sinaes in the management of higher education: micropolitical analysis \\ Implicaciones del Sinaes en la gestión de la educación superior: análisis micropolítica
}

Cristiane Fernandes - Instituto Federal de Educação Ciência e Tecnologia do Paraná - IFPR | Pedagoga |

Jacarezinho |PR | Brasil. E-mail: cristianefernandes.pedagoga@outlook.com DorciD

Maria Eliza Nogueira Oliveira - Universidade do Oeste Paulista - UNOESTE | Programa de Pós-Graduação em Educação | Presidente Prudente | SP | Brasil. E-mail: mariaeliza_oliveira@yahoo.com.br Dorcı

\author{
Regilson Maciel Borges - Universidade Federal de Lavras - UFLA | Departamento de Educação | Lavras | MG | \\ Brasil. E-mail: regilsonborges@gmail.com (1) ORcID
}

Resumo: O artigo problematiza as implicações do Sistema Nacional de Avaliação da Educação Superior (SINAES) com base em uma pesquisa realizada em dois cursos de graduação de duas Instituições de Ensino Superior (IES): uma pública e uma privada. Na pesquisa, são analisados documentos institucionais, questionários aplicados a alunos e docentes dos respectivos cursos e entrevistas semiestruturadas realizadas com os gestores das IES. A abordagem teórica da pesquisa foi construída com base nos estudos que analisam as instituições na perspectiva micropolítica, cujo objetivo é compreender como os sujeitos processam, ressignificam e reproduzem as políticas delineadas no âmbito dos governos - neste caso, as políticas de avaliação -, conferindo novos sentidos a suas experiências que podem contribuir com a superação e/ou manutenção da ordem capitalística em curso. Em ambas as instituições analisadas, os dados evidenciam que, em conformidade com uma perspectiva gerencial, a busca por resultados vem se convertendo em uma prática naturalizada criadora de uma identidade institucional que passa a ser compartilhada entre os gestores independentemente do tipo de instituição onde atuam.

Palavras-chave: Avaliação institucional. Gestão educacional. SINAES.

Abstract: The article discusses the implications of the National Evaluation System for Higher Education (SINAES) based on a research carried out in two graduation courses from two Higher Education Institutions: one public institution and a private one. In the research, institutional documents, questionnaires applied to students and professors from the respective courses and semi-structured interviews with the institutions' managers are analyzed. The theoretical approach of the research is based on the studies which analyze the institutions in the micropolitical perspective, whose goal is to understand how the subjects process, resignify and reproduce the policies outlined in the governments scope - in this case, the evaluation policies -, giving new meaning to their experiences that may contribute to the overcoming and/or maintenance of the current capitalist order. In both institutions, data demonstrate that, when under a management perspective, the search for results is increasingly changing into a natural practice that creates an institutional identity to be shared among the managers regardless the type of institution they operate.

Keywords: Institutional Evaluation. Educational Management. SINAES.

Resumen: El artículo aborda las implicaciones del Sistema Nacional de Educación de la Evaluación Superior (SINAES) sobre la base de una investigación realizada en dos cursos de graduación de dos Instituciones de Enseñanza Superior (IES): una pública y una privada. En la investigación, son analizados documentos institucionales, cuestionarios aplicados a alumnos y docentes de los respectivos cursos y entrevistas semiestructuradas realizadas con los gestores de las IES. El abordaje teórico de la investigación fue construido sobre la base de los estudios que analizan las instituciones en la perspectiva micropolítica, cuyo objetivo es comprender como los sujetos procesan, resignifican y reproducen las políticas delineadas en el ámbito de los gobiernos -en este caso, las políticas de evaluación-, lo que confiere nuevos sentidos a sus experiencias que pueden contribuir con la superación y/o manutención de la orden capitalista en curso. En ambas instituciones analizadas, los datos evidencian que, en conformidad con una perspectiva administrativa, la búsqueda por resultados se viene convirtiendo en una práctica naturalizada, criadora de una identidad institucional que pasa a ser compartida entre los gestores, independientemente del tipo de institución en la que actúan.

Palabras clave: Evaluación institucional. Gestión educacional. SINAES

• Recebido em 27 de agosto de 2018 • Aprovado em 02 de maio 2019 • e-ISSN: 2177-5796

DOI: http://dx.doi.org/10.22483/2177-5796.2019v21n2p611-636

Copyright @ 2019. Conteúdo de acesso aberto, distribuído sob os termos da Licença Internaonal da CreativeCommons - CC BY-NC-SA Atribuição Não Comercial (https://br.creativecommons.org/licencas/) - Permite distribuição e reprodução, desde que atribuam os devido créditos à publicação, ao autor(es) e que licenciem as novas criações sob termos idênticos. 


\section{Introdução}

Dentre os diversos temas que se destacam no contexto do debate acadêmico, seguramente, a avaliação institucional se impõe tanto por sua relevância, considerando o impacto que ela tem gerado nos aspectos organizacionais das instituições de ensino, quanto por sua complexidade, pois envolve processos subjetivos que se refletem nas práticas dos sujeitos que a vivenciam. Entendemos que essas práticas apenas podem ser estudadas e compreendidas a partir da imersão dos pesquisadores no ambiente institucional e por meio da aplicação de procedimentos e métodos de pesquisa que deem a elas visibilidade, permitindo que sejam analisadas sob diversas ópticas.

$\mathrm{Na}$ pesquisa que apresentaremos neste artigo, a óptica adotada foi a micropolítica, cuja problemática central consiste em "agenciar os processos de singularização no próprio nível em que elas emergem" (GUATTARI; ROLNIK, 2013, p. 152). O exercício de agenciar processos exige que o pesquisador considere, em sua análise, os diferentes modos de apreensão da realidade e a multiplicidade de aspectos envolvidos na construção de um dado contexto. Nossa escolha se orientou pelo interesse em compreender como os sujeitos processam, ressignificam e reproduzem as políticas delineadas no âmbito dos governos - neste caso, as políticas de avaliação permeadas pela intenção de capturar desejos, produzindo e reproduzindo comportamentos que contribuam com a manutenção do sistema social e econômico vigente.

Pautando-se em autores que analisam as instituições como produtoras de subjetividade (GUATTARI; ROLNIK, 2013; DELEUZE; GUATTARI, 2012; LOURAU, 1993; BAREMBLITT, 2002; BENELLI, 2010), buscou-se compreender como as IES vêm se organizando enquanto espaço de formação dos sujeitos e as possibilidades de produção de "implicação subjetiva", "de autonomia" e de "subjetividade singularizada". De acordo com Benelli (2010), consideramos que os três campos de produção estão interligados e podem resultar no desenvolvimento da capacidade de posicionar-se ativamente diante dos conflitos e contradições vivenciadas no cotidiano de modo a permitir que os sujeitos não sejam apenas "efeitos" e "reprodutores" desses conflitos e contradições, mas possam trabalhar no sentido de sua "metabolização" e "superação".

Eu oporia a essa máquina de produção de subjetividade a ideia de que é possível desenvolver modos de subjetivação singulares, aquilo que poderíamos chamar de "processos de singularização": uma maneira de recusar todos esses modos de 
FERNANDES, Cristiane; OLIVEIRA, Maria Eliza Nogueira; BORGES, Regilson Maciel. Implicações do Sinaes na gestão da educação superior: análise micropolítica.

encodificação preestabelecidos, todos esses modos de manipulação e de telecomando, recusá-los para construir, de certa forma, modos de sensibilidade, modos de relação com o outro, modos de produção, modos de criatividade que produzem uma subjetividade singular (GUATTARI; ROLNIK, 2013, p. 22).

Acreditamos que, apesar da força que os diversos mecanismos engendrados pelo Estado para "formatar" os sujeitos nos moldes que atendam às suas expectativas e demandas, há sempre fissuras no interior dos sistemas que possibilitam a estes mesmos sujeitos escapar a esses esquemas de formatação e reorganizar suas práticas no sentido do atendimento de outros interesses. Diante da ameaça que este campo de possibilidades representa às camadas sociais dominantes e à manutenção de seus privilégios, os "equipamentos coletivos" de produção de subjetividades têm se tornado cada vez mais sofisticados, sendo necessário tornar aparente seu modo de funcionamento, favorecendo a abertura de novas fissuras que permitam aos sujeitos resistir e atuar no sentido da produção de novas práticas e singularidades que escapem ao preestabelecido. A partir desse entendimento, a pesquisa que apresentamos analisou, de modo geral, as influências das políticas de avaliação externas vigentes no Brasil e, em um patamar mais específico, suas implicações na gestão de duas instituições de ensino superior, sendo uma pública e a outra privada. A pesquisa buscou analisar as experiências de gestores, coordenadores, docentes e discentes, frente ao atual Sistema Nacional de Avaliação da Educação Superior (SINAES).

Além de outros aspectos que serão apresentados e problematizados neste artigo, a pesquisa revelou as pressões internas e externas vivenciadas pelos sujeitos durante o processo avaliativo e as intencionalidades do sistema nacional de avaliação que, ao ser executado, faz emergir concepções, valores e crenças muito próximos daqueles defendidos nos discursos neoliberais, particularmente no que diz respeito à supervalorização de habilidades necessárias à superação individualizada dos limites postos pela realidade social, desenvolvidas com auxílio de equipamentos coletivos que despertam o desejo de competição e de busca por resultados intimamente relacionados à necessidade de reconhecimento e aprovação da instituição e, consequentemente, dos próprios sujeitos que a compõem, criando um certo tipo de identidade.

A produção do conhecimento, o compromisso com a racionalidade, a experiência da pesquisa e o exercício criativo da crítica constituem as funções centrais das instituições de ensino superior desde a sua origem (BARATA-MOURA, 2004). Todavia, o "como" e o "para quê" envolvidos no processo de produção do conhecimento vão se ressignificando e tomando novos 
FERNANDES, Cristiane; OLIVEIRA, Maria Eliza Nogueira; BORGES, Regilson Maciel. Implicações do Sinaes na gestão da educação superior: análise micropolítica.

contornos a partir dos processos históricos, econômicos e sociais definidores da identidade institucional.

O modelo de avaliação adotado pelo SINAES reflete as mudanças de concepções acerca da função do ensino superior nas últimas décadas. Amplamente defendida pelos organismos multilaterais, sobretudo a Organização para a Cooperação e Desenvolvimento Econômico (OCDE) e o Banco Mundial, as avaliações externas em larga escala têm utilizado, como parâmetro para aferir a qualidade das instituições educacionais dos países, indicadores de desempenho dos alunos em provas que avaliam competências e habilidades profissionais e acadêmicas delineadas mediante as demandas formativas de mercado. Embora o discurso oficial, difundido pelos órgãos centrais responsáveis pela formulação dos instrumentos avaliativos, aponte a avaliação em larga escala como um instrumento essencial para a garantia da qualidade do ensino ofertado pelas instituições escolares, na prática, estes instrumentos têm se convertido em dispositivos de regulação capazes de determinar os modos de funcionamento das IES.

Os rankings produzidos pelos órgãos de avaliação divulgados nos diversos meios de comunicação de massa (televisão, redes sociais, rádios e sítios eletrônicos), ampliam a visibilidade dos cursos e das IES, provocando uma grande corrida por resultados, que consiste em preencher os requisitos estabelecidos no próprio instrumento de avaliação onde se definem o currículo, baseado em competências e habilidades, e, consequentemente, o modo de organização do trabalho pedagógico.

Neste artigo, buscaremos problematizar a concepção de qualidade em que se baseiam as Políticas de Avaliação para a Educação Superior no Brasil a partir do modo como as políticas de avaliação vêm sendo vivenciadas por gestores, coordenadores de cursos, professores e estudantes de dois cursos pertencentes a duas instituições de ensino superior situadas no norte do Paraná, sendo uma pública e a outra privada. A pesquisa tomou como referência os resultados alcançados no último Exame Nacional de Desempenho de Estudantes (ENADE) por cada um dos cursos (2014 e 2015). Em termos de desempenho no ENADE, o curso da instituição pública obteve conceito superior em relação ao curso da instituição privada, o que nos despertou o interesse em conhecer os processos vivenciados anteriormente e posteriormente à produção desses resultados em cada um dos espaços e problematizá-los.

Inicialmente, os pesquisadores consideraram a possibilidade de forte influência e consideráveis implicações dos resultados das avaliações nas ações promovidas por parte dos 
FERNANDES, Cristiane; OLIVEIRA, Maria Eliza Nogueira; BORGES, Regilson Maciel. Implicações do Sinaes na gestão da educação superior: análise micropolítica.

responsáveis pela gestão institucional, pressupondo que estes resultados implicariam em mudanças substanciais nas práticas de gestão e nas práticas avaliativas dos cursos de graduação analisados. Todavia, a direção em que estas mudanças se deram, as perspectivas implicadas no processo e o alcance das ações em termos de resultados eram elementos ainda desconhecidos que procuramos compreender ao longo da nossa investigação.

A pesquisa pretendeu contribuir com o aprofundamento das discussões a respeito dos processos de avaliação da educação superior, mediante a forte expectativa da comunidade acadêmica na revisão de seus processos avaliativos. Acreditamos que a problemática da avaliação externa não diz respeito apenas aos que atuam na Educação Superior, mas a toda sociedade, pois, no atual contexto globalizado, é neste nível de ensino que, do ponto de vista político, influenciam-se as condutas e as representações de futuros quadros dirigentes do país e, do ponto de vista ideológico, presencia-se a imposição de um "esquema de homogeneização cultural e de valores", que reduz as possibilidades de diálogo intercultural (BARATA-MOURA, 2004, p. 34). Portanto, acreditamos que, ao apresentar e analisar os dados coletados em dois contextos específicos - à luz de referenciais que analisam as instituições a partir dos relatos de experiências dos sujeitos - contribuiremos com o debate em torno da função da Educação Superior no Brasil no contexto das políticas avaliativas em curso.

\section{Considerações gerais a respeito das Políticas de Avaliação da Educação Superior no Brasil}

Conforme analisa Dias Sobrinho (2010, p. 199), no contexto da acelerada expansão do ensino superior, ocorreu uma mudança qualitativa na finalidade deste nível de ensino, cujos objetivos, tradicionalmente defendidos, fragmentaram-se.

\footnotetext{
Muitas das múltiplas finalidades se vinculam agora aos objetivos dos grupos implicados e aos interesses particularistas dos diversos segmentos sociais. De modo destacado, têm grande força de determinação as questões relacionadas com o mundo do trabalho, as profissões e os empregos. Em outras palavras, a Educação Superior é levada a assumir uma função mais orientada ao individualismo possessivo e ao pragmatismo econômico que aos ideais do conhecimento universal, da pertinência e da justiça social. Isto equivale a dizer que o conhecimento e a formação estão crescentemente perdendo seus sentidos de bens públicos e direitos de todos e adquirindo mais e mais o significado de bens privados para benefício individual (DIAS SOBRINHO, 2010, p. 199).
} 
FERNANDES, Cristiane; OLIVEIRA, Maria Eliza Nogueira; BORGES, Regilson Maciel. Implicações do Sinaes na gestão da educação superior: análise micropolítica.

Além da fragmentação nos objetivos das IES, que passaram a adequar seus cursos às demandas locais e aos interesses privados, outro problema identificado pelo autor se refere ao perfil dos estudantes que passam a frequentar o ensino superior com "importantes déficits de formação acadêmica anterior, dificuldades econômicas e expectativas profissionais bastante limitadas" (DIAS SOBRINHO, 2010, p. 199). Para garantir o atendimento a esta pluralidade de perfis estudantis e conservar reservas de lucro provenientes do preenchimento das vagas ofertadas, as IES privadas diversificaram, consideravelmente, o perfil dos cursos no que diz respeito à "imagem social, duração de cursos, qualidade de serviços educativos, preços e estilos administrativos e organizacionais" e assim,

[...] o estudante dessas instituições, agora transformado em consumidor, passou a ter ampla gama de opções de ofertas de serviços educativos e a poder escolher o curso que se coaduna com seus interesses e recursos, objetivando obter o título ou o diploma que lhe dê melhores condições para competir na faixa do mercado que corresponde às suas expectativas e possibilidades (DIAS SOBRINHO, 2010, p. 199).

Diante desta diversidade de cursos, a avaliação externa surge como instrumento catalisador, visando ao alcance de resultados e metas definidos com o objetivo de capacitar, tecnicamente, os alunos para o emprego, limitando o alcance de propósitos educativos mais amplos. Além dos resultados dessas avaliações externas serem tomados para fins de marketing e propaganda pelas IES, nesse sentido "uma boa situação no ranking produz uma imagem favorável no mercado, aumenta a atratividade e os benefícios econômicos" (DIAS SOBRINHO, 2010, p. 207).

Cabe ressaltar que a consolidação dos sistemas de avaliação em larga escala no Brasil é bastante recente, alcançando seu reconhecimento como política nacional na década de 1990, após a aprovação da atual Lei de Diretrizes e Bases da Educação Nacional (LDB) - Lei n 9394/96, de 24 de dezembro de 1996, que, em seu art. 9, inciso VI, atribui à União a função de "assegurar processo nacional de avaliação do rendimento escolar no ensino fundamental, médio e superior, em colaboração com os sistemas de ensino, objetivando a definição de prioridades e a melhorias da qualidade do ensino" (BRASIL, 1996). A partir desta prerrogativa, os sistemas de ensino foram criando e aperfeiçoando diversos mecanismos de avaliação e fortalecendo seus processos de regulação em busca do alcance de metas (BROOKE; CUNHA, 2011). Em análises a respeito dos processos avaliativos nas organizações modernas, Minhoto (2016) atribui-lhes duas funções distintas: 1) levantar informações ou evidências necessárias à formulação de políticas 
educacionais, tendo como propósito ampliar e aprofundar o conhecimento sobre os sistemas de ensino para que as diferentes esferas de governo possam definir prioridades de intervenção; e 2) induzir mudanças ou consolidar reformas educacionais previamente estruturadas para os sistemas de ensino. Embora, aparentemente, as duas funções explicitadas pela autora guardem algumas especificidades e persigam diferentes objetivos, o que se tem observado a partir de nossas vivências e pesquisas é a sobreposição da segunda função sobre a primeira e sobre as demais funções próprias dos mecanismos de avaliação (FERNANDES, 2017; OLIVEIRA, 2015). Da organização curricular à organização do trabalho pedagógico em sala de aula, vê-se a preocupação dos gestores, coordenadores de cursos e docentes com as avaliações externas, que acabam por incentivar práticas de treinamento de alunos por meio da constante aplicação de atividades padronizadas que tomam como "modelo" as provas aplicadas nos anos anteriores e seus descritores.

Na Educação Superior brasileira, esses processos ganharam visibilidade e consistência a partir dos anos 1990, quando se experimentou a implantação de grandes sistemas de avaliação em larga escala, representados à época no Programa de Avaliação Institucional das Universidades Brasileiras (PAIUB), em 1993, e no Exame Nacional de Cursos (ENC), que ficou conhecido como "Provão", em 1995. Após oito anos de vigência do ENC/Provão, em 2004 é inaugurado o atual Sistema Nacional de Avaliação do Ensino Superior (SINAES), no governo Lula. Instituído pela Lei $\mathrm{n}^{\mathrm{o}}$ 10.861, de 14 de abril de 2004 (BRASIL, 2004), o SINAES se fundamenta na necessidade de promover a melhoria da qualidade da educação superior, a orientação da expansão de sua oferta, o aumento permanente de sua eficácia institucional, da sua efetividade acadêmica e social e, especialmente, do aprofundamento dos seus compromissos e responsabilidades sociais.

O SINAES é formado por três modalidades principais de instrumentos de avaliação aplicados em momentos distintos: a Avaliação das Instituições de Educação Superior (AVALIES), a Avaliação dos Cursos de Graduação (ACG) e a Avaliação do Desempenho dos Estudantes através do Exame Nacional de Avaliação do Desempenho dos Estudantes (ENADE). Apesar desta composição, o ENADE acabou ganhando maior destaque por ser firmado como “componente curricular obrigatório dos cursos de graduação, sendo inscrita no histórico escolar do estudante somente a sua situação regular com relação a essa obrigação, atestada pela sua efetiva participação ou, quando for o caso, dispensa oficial pelo Ministério da Educação, na forma estabelecida em regulamento" (BRASIL, 2004). 
FERNANDES, Cristiane; OLIVEIRA, Maria Eliza Nogueira; BORGES, Regilson Maciel. Implicações do Sinaes na gestão da educação superior: análise micropolítica.

Deste modo, o ENADE vem ocupando espaço de destaque nos cursos de graduação e na vida escolar dos alunos que - de maneira mais expressiva nas instituições privadas - passam a ser treinados, periodicamente, por seus professores - em obediência às exigências de seus coordenadores de cursos - esvaziando o sentido da avaliação como instrumento de análise do processo de ensino e aprendizagem, portanto, parte fundamental de todo o processo pedagógico (FERNANDES, 2017).

O ENADE, tal como concebido, consiste num instrumento de avaliação a diagnosticar, geralmente a cada três anos, as habilidades acadêmicas e as competências profissionais que os estudantes são capazes de demonstrar, em conexão com suas percepções sobre sua instituição e com conhecimentos gerais não necessariamente relacionados com os conteúdos disciplinares. Como tal, deveria ser considerado como um dos componentes do sistema de avaliação, não devendo ser tomado isoladamente (DIAS SOBRINHO, 2010, p. 212).

O ENADE é um exame nacional aplicado aos cursos a cada três anos com objetivo de avaliar o desempenho dos alunos e diagnosticar "as habilidades acadêmicas e as competências profissionais que os estudantes são capazes de demonstrar, em conexão com suas percepções sobre sua instituição e com conhecimentos gerais não necessariamente relacionados com os conteúdos disciplinares" (DIAS SOBRINHO, 2010, p. 212). Aplicado a alunos concluintes dos cursos selecionados para o exame, o ENADE possibilita as competências e habilidades adquiridas pelos estudantes por meio da análise de problemas, situações e teorias indicados nas questões a eles propostas. $\mathrm{O}$ autor considera que, em termos de finalidade, o ENADE se aproxima de uma concepção formativa de avaliação, pois não tem o objetivo de controlar e verificar os conteúdos disciplinares, mas "conhecer os avanços, superar as dificuldades e atribuir um sentido ao processo educativo".

Por isso, não poderia dar margem a rankings e nem ser a ferramenta mais importante para efeitos de regulação. Quando tecnicamente mal sustentados e politicamente equivocados, os rankings produzem injustiça e injetam rivalidades entre IES de diversas naturezas e distintos grupos profissionais, competitividade e práticas típicas de mercado e desvios das finalidades essenciais da formação em educação superior (DIAS SOBRINHO, 2010, p. 214).

Ainda que o sentido original do ENADE não seja o fortalecimento dos rankings, Dias Sobrinho (2010) considera que a própria Lei do SINAES justifica a elaboração de rankings quando estabelece a escala de cinco níveis para os cursos e para o desempenho dos estudantes. Esta estratégia é considerada uma contradição do próprio sistema que, em sua proposta inicial, 
FERNANDES, Cristiane; OLIVEIRA, Maria Eliza Nogueira; BORGES, Regilson Maciel. Implicações do Sinaes na gestão da educação superior: análise micropolítica.

determinou a não fragmentação da avaliação, respeitando a identidade institucional e a diversidade do sistema, valorizando, inclusive, os processos de avaliação interna.

$\mathrm{Na}$ compreensão do autor, a utilização dos rankings reflete a própria dificuldade dos órgãos de avaliação de operacionalizar um sistema avaliativo em âmbito nacional que considere a imensa desigualdade e diversidade sociocultural do nosso país.

Dificuldades operacionais e escassa compreensão de alguns aspectos do paradigma do SINAES estão levando a avaliação institucional a se burocratizar, tornando pouco relevante o papel das CPAs (Comissões Próprias de Avaliação) e praticamente abafando as reflexões dos professores, estudantes e funcionários. O estudante voltou a ser a principal fonte de informação para a formulação dos índices de qualidade e das políticas que daí derivam. A avaliação da Educação Superior brasileira tende a ser crescentemente um instrumento de classificação de cursos e instituições (DIAS SOBRINHO, 2010, p. 216).

A adoção de rankings tem sido uma técnica muito comum nas instituições educacionais em geral. Trata-se de um mecanismo eficiente, de caráter gerencial, cujo objetivo é estimular a competitividade e o aumento da produção controlado a partir de índices e metas. A transferência do modelo administrativo empresarial para as instituições educacionais não é recente e vem sendo defendida por alguns autores da administração educacional desde a década de 1950 (RIBEIRO, 1952; ALONSO, 1976). No entanto, foi na década de 1990, com o advento das políticas reformistas neoliberais, que este modelo começou a ganhar mais força, passando a ser operacionalizado no âmbito dos sistemas, alterando, significativamente, a dinâmica das instituições de ensino.

O modelo de gestão empresarial tem sido adotado com cada vez mais frequência nas diversas instituições, incluindo as educacionais, como parte de um "processo de empresariamento" da sociedade que se inicia nas primeiras décadas do século XX. Em sua fase inicial, datada dos anos de 1960 a 1970, desenvolveu-se um conjunto de "valores, princípios, normas, procedimentos, tecnologias, mecanismos e normas de condutas", próprio do mundo corporativo empresarial capitalista, que passou a migrar para além dos limites organizacionais, "espraiando-se para outras esferas da sociedade e por entre a vida cotidiana dos indivíduos e das populações nas grandes metrópoles e cidades dos países desenvolvidos", redefinindo e transformado "as relações que mantinham com o tempo e o espaço, bem como a relação com o consumo, os modos e estilos de vida, redesenhando inteiramente, portanto, essas sociedades" (GADELHA, 2017, p. 125). 
FERNANDES, Cristiane; OLIVEIRA, Maria Eliza Nogueira; BORGES, Regilson Maciel. Implicações do Sinaes na gestão da educação superior: análise micropolítica.

No caso específico da educação, esta passa a ser seriamente criticada por ter se deixado guiar cada vez mais por estes valores, assumindo um caráter instrumental, convertendo-se

[...] numa espécie de grande dispositivo psicopedagógico e técnico-científico de adestramento e sujeição dos corpos-subjetividades infanto-juvenis, munindo o sistema de produção capitalista das forças vitais necessárias ao seu bom funcionamento e garantindo a docilidade política dos indivíduos e coletividades, de modo a facilitar a adaptação passiva destes aos novos mecanismos de governo e regulação das condutas, induzindo-os, inclusive, a reivindicarem mais vigilância e controle sobre suas vidas (GADELHA, 2017, p. 130).

Gadelha (2017) julga ser o culto ao desempenho e a centralidade nos processos de avaliação as expressões mais fortes do que ele denomina "adestramento contemporâneo dos corpos-subjetividades", que acabaram por se converter em uma importante estratégia a administradores e gestores. Para explicar melhor esta relação entre o culto ao desempenho, o adestramento coletivo e a gestão, o autor vale-se da análise de Coelho Júnior (2015) que, entre outras considerações, assinala que, desde o início do século XX, nos anos 1910, os resultados de avaliações passaram a servir como forma de comunicar os gestores a respeito do status do trabalho executado pelos subordinados e como apoio aos processos de tomada de decisões realizados com base nessas informações.

O uso de medidas de aferição do desempenho nas organizações objetivava fornecer insumos consistentes ao redesenho de práticas e políticas organizacionais. Essa é a justificativa para que, desde os primórdios, o foco no gerenciamento de desempenho consistisse principalmente na etapa de avaliação. Mais recentemente, a partir da segunda fase da Revolução Industrial (meados de 1945), a avaliação de desempenho passou a ser concebida como tática às ações de capacitação. Descrições de cargo fundamentavam as políticas de recrutamento, seleção e eram a base para a formulação de indicadores de desempenho. A partir de 1990, com a gênese e consolidação dos programas de gestão por competências nas organizações, a gestão do desempenho emergiu como tática e passou a figurar como elemento-chave no planejamento de trabalho. A aquisição de competências seria facilitada por ações de gestão focadas na maximização da performance. Assim, mais do que simplesmente avaliar, interessava se desenvolver outras etapas de gestão em todos os níveis (individual, grupal e contextual) com foco no planejamento, monitoramento, avaliação e revisão. Essa é a perspectiva atual (COELHO JÚNIOR, 2015 apud GADELHA, 2017, p. 131).

A análise dos autores nos possibilita compreender os mecanismos avaliativos adotados por instituições de ensino superior, cujo eixo fundamental é a avaliação do desempenho dos alunos. As técnicas de avaliação de desempenho dizem respeito não apenas ao alcance de resultados e metas, mas, mais do que isto, induzem à adoção de determinados tipos de 
comportamentos requeridos que reforçam o modo de organização social necessário para sustentar o sistema capitalista de produção, como a competitividade e o reforço do mérito.

Neste sentido, consideramos que os exames, no formato que vêm sendo aplicados nas IES, convertem-se não apenas em instrumentos de função diagnóstica, mas, sobremaneira, perseguem uma função descritiva e de controle. Utilizando o conceito desenvolvido por Guattari e Rolnik (2013), funcionam como verdadeiras “máquinas de produção de subjetividades".

No decurso em que se efetiva essa produção, os indivíduos são "reduzidos a engrenagens concentradas sobre o valor de seus atos, valor que responde ao mercado capitalista e seus equivalentes gerais" (GUATTARI; ROLNIK, 2013, p. 52). A ordem capitalística produz, e por que não dizer determina, os modos das relações humanas, alocando tudo o que representa uma ruptura com o pré-estabelecido em "registros de referência dominantes". Assim, os modos de ensinar, de avaliar, de organizar e coordenar o processo pedagógico, inscrevem-se em um parâmetro universal, ainda que estes parâmetros tenham sido construídos sob o pretexto da valorização das particularidades (GUATTARI; ROLNIK, 2013).

Outra variável destacada por Gadelha (2017, p. 135), e que faz parte dos mecanismos de regulação pela via da avaliação de desempenho, é o culto da gestão, que o autor concebe como um "dispositivo de normatividade social” que converte problemas de diversas natureza (política, psicossocial e/ou cultural) em questões empresariais, cuja solução depende, única e exclusivamente, da aplicação de técnicas adequadas capazes de controlar as variáveis que se apresentam como elementos desviantes geradores de conflitos nas organizações.

A terceira variável presente nesta relação entre governamentalidade neoliberal, educação e processos de subjetivação apresentada por Gadelha (2017) é o da "visibilidade/transparência". Segundo o autor, esta variável afeta diretamente os indivíduos - que passam a sofrer com as práticas exibicionistas ("funcionário do mês", "professor do ano", "funcionário nota 10" etc.) - e acaba por estimular a competição entre pares e a necessidade de criar técnicas de espetacularização que ampliem a visibilidade do desempenho individual. Esta variável passa, portanto, a imperar nas instituições que começam a investir em serviços de marketing para dar visibilidade à "qualidade" dos serviços prestados (GADELHA, 2017).

Não é raro que as IES utilizem os conceitos alcançados pelos cursos no ENADE como propaganda para atrair alunos, ainda que estes conceitos, nem sempre, reflitam a qualidade no trabalho desenvolvido. Em nome da transparência, a conquista ou a manutenção de maiores notas 
FERNANDES, Cristiane; OLIVEIRA, Maria Eliza Nogueira; BORGES, Regilson Maciel. Implicações do Sinaes na gestão da educação superior: análise micropolítica.

nas avaliações passa a ser o maior objetivo do gestor, cujo papel é liderar os demais de modo que todos possam "vestir a camisa" em busca da produção ou manutenção dos melhores resultados. Sousa (2008, p. 93) ressalta que, "no contexto competitivo da educação superior", "tudo indica que o marketing tem sido considerado por um grande número de IES uma 'ferramenta de gestão"”.

Apesar das práticas de controle aqui apresentadas, as IES abrigam sujeitos e não estão imunes aos focos de resistência capazes de produzir novos processos de singularização que atribuam outros/novos sentidos às práticas cotidianas. Resta-nos saber, numa perspectiva analítica micropolítica, em que medida esses sujeitos reproduzem ou não os modos de subjetividades dominantes. Mais do que isso, importa-nos captar as práticas que "bloqueiam os processos de transformação no campo subjetivo que se dão nos vários campos de experimentação social” (GUATTARI; ROLNIK, 2013, p. 158).

\section{Abordagem da pesquisa}

O estudo dos avanços e limitações da avaliação em larga escala nos países latinoamericanos e na América do Norte, considerando seu percurso histórico e sua relação com os acordos multilaterais firmados em escala mundial, despertou-nos o interesse de ampliar as análises dos processos de concretização da Lei do SINAES no cotidiano das instituições de ensino superior brasileiras, bem como, seu impacto na gestão das IES mediante os resultados alcançados (HADDAD, 2008; RAVITCH, 2011; DIAS SOBRINHO, 2010) ${ }^{1}$. Os dados que serviram de base para o desenvolvimento desta pesquisa foram coletados em duas instituições de ensino superior, uma pública e outra privada, localizadas no norte do Paraná.

A escolha dos cursos analisados se deu a partir do levantamento do ENADE que antecedeu o início do estudo. Assim, optamos por investigar um curso ofertado por uma Instituição de Ensino Superior Privada (IESP) e outro curso de uma Instituição de Ensino Superior Pública (IESF), sendo o primeiro um curso com baixo conceito no ENADE 2014 e o segundo um curso com alto conceito no ENADE 2015. Após o contato com as instituições, foram

\footnotetext{
${ }^{1}$ No ano de 2016, o Grupo de Estudos e Pesquisas "Estado, Políticas Educacionais e Democracia", da Universidade do Oeste Paulista (UNOESTE), elegeu como tema de estudo as políticas regulatórias nos países do continente americano e sua correspondência com as diretrizes do Banco Mundial. Neste período, foram realizados levantamentos de estudos que abordam a temática com foco nas avaliações em larga escala.
} 
FERNANDES, Cristiane; OLIVEIRA, Maria Eliza Nogueira; BORGES, Regilson Maciel. Implicações do Sinaes na gestão da educação superior: análise micropolítica.

escolhidas 64 pessoas para participarem, sendo 32 pessoas de cada IES pesquisada, compreendendo, 25 discentes, 5 docentes, 1 coordenador de curso e o diretor de cada Instituição. Dadas as diferenças e especificidades de cada um dos espaços investigados, o objetivo da pesquisa não correspondeu a um estudo comparativo, mas um estudo que nos permitisse compreender o impacto do SINAES na gestão de duas instituições de ensino superior.

Após o contato com os participantes da pesquisa, que aceitaram colaborar voluntariamente mediante apresentação e assinatura de Termo de Consentimento Livre e Esclarecido (TCLE), foi garantida a preservação de suas identidades a partir do uso dos seguintes códigos: GP (Gestor da Instituição de Ensino Superior Privada); CP (Coordenador da Instituição de Ensino Superior Privada); GF (Gestor da Instituição de Ensino Pública); CF (Coordenador da Instituição de Ensino Superior).

Os dados da pesquisa foram coletados por meio de questionários, entrevistas semiestruturadas e leitura dos seguintes documentos: Plano de Desenvolvimento Institucional (PDI), Projeto Pedagógico Institucional ou Projeto Político-pedagógico (PPI ou PPP), Projeto Pedagógico de Curso (PPC), Projeto de Avaliação Institucional (CPA), Relatórios da Comissão Própria de Avaliação (CPA), correspondentes ao ano com realização do último ENADE na IES e o ano subsequente ao evento, Relatórios da Comissão de Avaliadores Externos (MEC) no último ciclo avaliativo do SINAES, relatórios do ENADE enviados pelo MEC à IES, Atas das reuniões de CPA e, por fim, as Atas de reuniões do Núcleo Docente Estruturante (NDE) do curso pesquisado.

Posteriormente ao levantamento dos documentos especificados, foram realizadas entrevistas semiestruturadas com os gestores de ambas as instituições, por entendermos que, por intermédio desse instrumento, ampliaríamos nossa compreensão acerca dos desdobramentos da avaliação institucional na organização dos cursos. No decorrer das entrevistas, os sujeitos relataram suas experiências e novas questões emergiram a partir desses relatos permitindo-nos revelar como esses sujeitos atuaram frente às exigências do SINAES e os modos de reprodução e produção de subjetividades engendrados no decorrer dessas experiências.

No roteiro da entrevista semiestruturada foram consideradas as seguintes dimensões:

1) Conhecimentos e interpretações a respeito do SINAES;

2) Estratégias utilizadas pela IES para o alcance de resultados; 
FERNANDES, Cristiane; OLIVEIRA, Maria Eliza Nogueira; BORGES, Regilson Maciel. Implicações do Sinaes na gestão da educação superior: análise micropolítica.

3) Participação dos docentes e discentes no processo avaliativo da IES; e

4) O tratamento dos resultados alcançados pela IES na avaliação institucional e seus impactos na gestão.

O último instrumento de coleta de dados consistiu na aplicação de um questionário similar aos docentes de cada IES que atuam nos cursos pesquisados e aos discentes que participaram do último ENADE dos referidos cursos, totalizando 60 respondentes, sendo 10 docentes (5 de cada IES) e 50 discentes (25 de cada IES). O objetivo central dos questionários aplicados foi o levantamento de dados e informações que permitissem compreender em que medida as informações coletadas nos documentos e nas entrevistas eram ou não compartilhadas por alunos e docentes dos cursos analisados. Todas as questões elaboradas se relacionaram diretamente às quatro dimensões das entrevistas aplicadas aos gestores dos cursos que, no processo de análise, foram traduzidas em três categorias principais: Sistema Nacional de Avaliação do Ensino Superior (SINAES), Participação e Gestão.

\section{Análise das implicações do SINAES na gestão das instituições pesquisadas}

Os dados coletados na fase inicial da pesquisa ajudaram-nos a compreender a dinâmica de funcionamento das instituições analisadas e em que medida o sistema de avaliação atual tem influenciado os processos organizativos, tanto pedagógicos quanto administrativos. Por aspectos pedagógicos, entendemos as ações que implicam diretamente na organização curricular - onde se explicitam as atividades avaliativas -, nos projetos disciplinares e interdisciplinares, nos métodos de ensino, entre outros elementos que se inter-relacionam com as atividades intra e extraescolares desenvolvidas com os alunos durante o percurso formativo.

Os processos administrativos, compreendidos como processos de mediação, relacionamse aos procedimentos engendrados no âmbito da gestão voltados ao alcance dos objetivos institucionais que se diversificam de acordo com o contexto, a natureza da instituição e os diversos interesses em jogo (LIMA, 2008). Neste processo, estão envolvidos desde os recursos despendidos e seus mecanismos de distribuição até as decisões em torno dos processos de atribuições de aulas, da carga-horária docente, dos mecanismos de captação de alunos, da regulamentação e normas a que estarão submetidos os diversos segmentos que compõem a 
FERNANDES, Cristiane; OLIVEIRA, Maria Eliza Nogueira; BORGES, Regilson Maciel. Implicações do Sinaes na gestão da educação superior: análise micropolítica.

organização e, especialmente, dos meios para garantir a participação ou limitá-la nos processos de tomada de decisões, sempre no sentido de atender os objetivos institucionais que podem ou não estar explícitos. Neste sentido, nosso interesse voltou-se para o nível de compartilhamento desses objetivos e acabamos por eleger como foco central da pesquisa a gestão nas duas IES analisadas, conforme explicitaremos mais adiante.

Com relação ao Plano de Desenvolvimento Institucional (PDI) e ao Projeto Pedagógico Institucional ou Projeto Político-Pedagógico (PPI ou PPP), buscamos apreender a organização pedagógica e administrativa da instituição e dos cursos, os objetivos educacionais, os aspectos materiais e estruturais e a correlação entre esses elementos e os resultados da avaliação institucional.

Nos documentos de ambas as instituições pesquisadas foi possível observar o atendimento das prerrogativas e orientações do Ministério da Educação no preenchimento dos itens especificados, o que resultou em documentos semelhantes no que diz respeito à sua apresentação. Todavia, em termos de conteúdo, os documentos da instituição pública apresentaram com maior clareza os aspectos estruturais, permitindo-nos obter maior visibilidade quanto aos aspetos organizacionais, sobremaneira, àqueles referentes à organização do trabalho pedagógico.

De acordo com os documentos, no que diz respeito à gestão, ambas as instituições atendem ao princípio da gestão democrática alicerçado na autonomia dos conselhos representativos e na participação dos segmentos que compõem a comunidade acadêmica.

Todavia, o modo de conceber a gestão democrática apresentou divergências:

É preciso que toda a comunidade compreenda que viver a experiência da gestão democrática da escola implica que todos estejam atentos em como isso ocorre no âmbito educativo escolar, e tenham por concepção que a própria sala de aula é um lugar de gestão e, principalmente, de aprendizagem da gestão democrática, não só da escola, mas da vida. Pois a gestão democrática deve ser compreendida como recurso de participação humana e de formação para a cidadania (PROJETO POLÍTICO PEDAGÓGICO DA IESF, 2015, p. 82). ${ }^{2}$

O compromisso institucional visou manter equilíbrio no domínio complexo da relação entre Autonomia, Financiamento e Avaliação, conforme orientações emanadas do MEC. Esse comprometimento baseou-se nos princípios de gestão democrática, resultado da qualidade, equidade, transparência e eficiência (PLANO DE DESENVOLVIMENTO INSTITUCIONAL DA IESP, 2017, p. 110).

\footnotetext{
${ }^{2}$ A presente pesquisa passou por aprovação do Comitê de Ética em Pesquisa da Universidade do Oeste Paulista (Processo CAAE $n^{\circ}$ 60374016.6.0000.5515) não sendo autorizada a identificação das instituições pesquisadas. Deste modo, não serão incluídas as referências dos documentos institucionais.
} 
FERNANDES, Cristiane; OLIVEIRA, Maria Eliza Nogueira; BORGES, Regilson Maciel. Implicações do Sinaes na gestão da educação superior: análise micropolítica.

No primeiro documento, observamos um conceito amplo de gestão democrática entendida como um "recurso de participação humana para a cidadania". Mais do que um princípio a ser seguido por força da lei, a gestão democrática, na instituição pública, funciona como um elemento formativo, com caráter pedagógico, cujo objetivo é desencadear um processo de aprendizagem - em que os sujeitos vivenciam a participação nos processos de tomada de decisões e ampliam os conhecimentos no que se refere aos aspectos que envolvem a consolidação dos processos democráticos de forma geral (“da vida") e não apenas no âmbito escolar.

No segundo caso, a concepção de gestão democrática volta-se à ideia de um instrumento para a manutenção de um "equilíbrio no domínio complexo na relação entre Autonomia, Financiamento e Avaliação", em atendimento às orientações do Ministério da Educação onde estes três elementos aparecem como condições básicas para a implementação das reformas na educação superior (FERREIRA, 2015, p. 123). Numa perspectiva sistêmica, a relação entre esses três elementos traduz uma concepção de avaliação institucional como instrumento utilizado para levantamento de um conjunto de informações que sirva de base para projetar ações comuns voltadas a correções das "falhas" identificadas no percurso em busca dos objetivos organizacionais. Neste caso, a concepção de gestão democrática se restringe à participação conjunta voltada à concretização das metas alinhadas com as propostas de superação dos problemas apontados pela avaliação e não ao projeto institucional construído com base no debate coletivo. A autonomia conferida às IES, neste caso, subordina-se aos indicadores de qualidade e desempenho definidos em âmbito macro que passam a orientar os processos de tomada de decisões, coletivas ou não, incluindo os de ordem financeira. Trata-se de uma autonomia regulada por princípios de "qualidade, equidade e transparência", em que o compromisso assumido pelas instituições equipara-se diretamente às prerrogativas das políticas regulatórias delineadas em âmbito global, restando muito pouco em termos de autonomia real articulada aos projetos das IES, com maior ênfase nas instituições privadas.

[...] E mesmo na educação superior, onde as instituições portuguesas gozam, em termos jurídicos, de amplas margens de autonomia, os últimos anos vêm acentuando dinâmicas de uma autonomia sitiada. Uma autonomia procedimental e limitada por efeito dos cortes de financiamento por parte do Estado, da adaptação a processos supranacionais de integração e a dinâmicas transnacionais de captação de financiamentos alternativos, de acordo com as orientações de um cânone gerencialista e de um complexo hibridismo institucional de feição inovadora e adaptativa ante o ambiente competitivo que, em ambos os casos, assentam na superioridade da racionalidade econômico-empresarial (LIMA, 2015, p. 1341). 
FERNANDES, Cristiane; OLIVEIRA, Maria Eliza Nogueira; BORGES, Regilson Maciel. Implicações do Sinaes na gestão da educação superior: análise micropolítica.

Apesar da diferença identificada nos documentos das duas instituições com relação à concepção de gestão democrática, observou-se nas entrevistas que os gestores da instituição pública compartilham a concepção sistêmica de avaliação, inclusive com o uso de termos utilizados nos estudos desta abordagem, como o termo "feedback", em que as informações coletadas servem de referências para a tomada de decisões nos moldes das exigências dos órgãos oficiais, conforme se constata na declaração de um dos entrevistados, em que este afirma contar com o auxílio de "docentes avaliadores" na estruturação dos cursos em "todos os departamentos da universidade".

[...] O nosso entendimento da política de avaliação no nosso país é de que esta é muito frutífera, proporcionando um feedback relevante aos gestores da IES e dos cursos, alicerçando nossas ações em busca de melhorias para o curso. (CF)

[...] O SINAES busca balizar as ações na universidade. (GF)

[...] Temos muitos docentes que são avaliadores do MEC e que nos auxiliam estruturando todos os departamentos da universidade para esse momento. (GF)

[...] A avaliação institucional como política pública me parece ter divergência quando se trata de IES privadas, ela é mais incisiva, mais crítica do que nas IES públicas. (CP)

[...] Temos conhecimento das políticas públicas para a avaliação institucional, porém, esta política ainda é obscura, não temos clareza de qual é seu objetivo fim. (GP)

Com base na leitura das atas de reuniões do Núcleo Docente Estruturante (NDE) dos cursos, constatamos que a elaboração do Projeto Pedagógico de Curso (PPC), nas instituições pesquisadas, é conduzida de diferentes formas. Na instituição pública, a construção deste documento é realizada coletivamente, com a participação de todos os membros do NDE do curso, e todo o processo é documentado em atas de reuniões que ocorrem de maneira sistemática e frequente.

$\mathrm{Na}$ instituição privada, o processo apresentou algumas limitações. Apesar da existência do Núcleo Docente Estruturante (NDE), sua atuação não se demonstrou efetiva, ficando a cargo da coordenação do curso a construção do PPC, o que reduz muito a possibilidade de um projeto mais próximo dos anseios da comunidade acadêmica, remetendo-nos à constatação de que se trata de um documento elaborado para fins burocráticos. Não há dúvida de que, quanto menos espaço é despendido para a elaboração coletiva dos objetivos educacionais, maior é a tendência da instituição em aderir a objetivos externos assentados em pressupostos que se distanciam daqueles que situam a Educação Superior na perspectiva do direito e não das exigências de mercado. 
FERNANDES, Cristiane; OLIVEIRA, Maria Eliza Nogueira; BORGES, Regilson Maciel. Implicações do Sinaes na gestão da educação superior: análise micropolítica.

Com relação à Comissão Própria de Avaliação (CPA), por meio da leitura do Projeto de Avaliação Institucional, dos relatórios correspondentes ao ano de realização do último ENADE na IES e ao ano subsequente ao evento, e das atas das reuniões de CPA, constatamos que, na instituição pública, a CPA está instalada, porém, sem grande notoriedade, atuando na elaboração e armazenamento de registros e documentos a serem apresentados ao MEC nas avaliações in loco, haja vista que a maioria expressiva dos alunos (22 dos 25 que responderam o questionário) apontaram o desconhecimento da CPA em sua instituição. Embora o coordenador de curso da IESF tenha relatado em sua entrevista que a CPA exerce papel fundamental no curso, nos questionários aplicados aos docentes, três dos cinco respondentes disseram não ter conhecimento da CPA.

Diferentemente da instituição pública, na instituição privada, a CPA é reconhecida por parte significativa da comunidade acadêmica: quatro dos cinco docentes e nove alunos, entre os 25 respondentes, disseram conhecer a comissão. Conquanto não seja um número expressivo de alunos, este dado revela que a participação dos membros da CPA na instituição privada é mais ativa, conforme apontado nos documentos. Além de organizar os processos avaliativos, a CPA informa, sistematicamente, aos docentes e discentes os assuntos relacionados ao processo de avaliação institucional, conscientizando-os, por meio de visitas frequentes às salas de aula, acerca da importância da participação na avaliação dos cursos, demonstrando empenho no levantamento de dados que possam orientar a gestão da IES, permitindo-a sanar as fragilidades e aprimorar a organização do trabalho pedagógico. Os registros dessas experiências, nos permitiram compreender que a CPA assume uma função de coordenação de ações estratégicas rumo a produção de melhores resultados nas avaliações externas voltadas aos cursos de graduação.

No que tange aos relatórios elaborados pela comissão de avaliadores externos do MEC, no último ciclo avaliativo do SINAES, no curso da instituição privada, o número de itens avaliados com notas regulares e insuficientes foi mais elevado do que no curso da instituição pública, resultando em baixo conceito. Observou-se que os comentários e apontamentos dos avaliadores externos foram mais incisivos, pontuais e minuciosos na IESP, do que na IESF. No entendimento dos gestores, este evento ganha o seguinte significado:

[...] Acredito que as instituições federais sempre esperam nota 4 ou 5 quando passam por avaliações do MEC, nós temos inclusive, uma avaliação que teve nota 4, e um 4 forte, quase 5. E acho que foi justa, acredito que não houve sequer uma avaliação externa que tenha sido discrepante ao geral já vivido por nossa IES. (CF) 
FERNANDES, Cristiane; OLIVEIRA, Maria Eliza Nogueira; BORGES, Regilson Maciel. Implicações do Sinaes na gestão da educação superior: análise micropolítica.

\section{[...] É importante ressaltar que nunca precisamos entrar com qualquer tipo de recurso. (CF)}

[...] Os resultados das avaliações refletem a realidade da universidade. (GF)

[...] Quando é disparado um processo avaliativo toda a estrutura da universidade se volta para atender esse momento importante para a IES. (GF)

[...] Os avaliadores do MEC chegam com um olhar das instituições federais e não consideram a realidade da instituição [privada] o que prejudica, em muito, os resultados alcançados pela IES. (CP)

[...] Os avaliadores são treinados de forma ineficaz, pelo MEC e não conseguem ser imparciais nas avaliações institucionais deixando a instituição a mercê de sua discricionariedade e subjetividade. (GP)

Explicita-se nas entrevistas um dos elementos mais complexos que compõe os processos avaliativos: a subjetividade do avaliador. Embora os instrumentos de avaliação tenham se tornado cada vez mais técnicos e objetivos não se pode garantir a ausência de inferências capazes de produzir dados incoerentes com a realidade observada a partir de critérios consolidados internamente carregados de valores e preferências. Todavia, essas inferências tendem a ser questionadas na medida em que desfavorecem aqueles que estão submetidos à avaliação, revelando a complexidade do processo avaliativo mediante a tendência em produzir novos dados, pautados em opiniões, que não reflitam a realidade observada.

Esse aspecto foi investigado de forma mais precisa por meio da leitura e análise dos diversos relatórios das visitas in loco realizadas pelos avaliadores do Ministério da Educação na IESP em que se revelaram divergências significativas. Enquanto um relatório trazia um conceito "muito bom" ou "excelente" (representado pelas notas 4 ou 5) em diversos itens, em outro relatório, os mesmos itens eram considerados insuficientes (nota 2). Conforme relatos dos entrevistados, devido à recorrência destas divergências, a IESP entrou com recurso junto à Comissão Técnica de Acompanhamento da Avaliação - CTAA -, todavia não obteve resultado positivo, fazendo-os crer que os aspectos subjetivos nas avaliações se sobrepõem aos aspectos objetivos, conforme o trecho da entrevista destacado anteriormente.

Com relação ao ENADE, os dados demonstraram posicionamentos divergentes no que diz respeito à preparação, aplicação e uso dos resultados. Estas divergências resultam das especificidades de cada instituição relacionadas aos aspectos administrativos e pedagógicos. De um lado, uma instituição que se assemelha a muitas IES situadas em municípios com número populacional de até 150 mil habitantes, ou seja, uma faculdade privada, de pequeno porte, com poucos cursos de graduação e, consequentemente, poucos alunos (pouco mais de 300 no caso da 
FERNANDES, Cristiane; OLIVEIRA, Maria Eliza Nogueira; BORGES, Regilson Maciel. Implicações do Sinaes na gestão da educação superior: análise micropolítica.

IES analisada). De outro lado, uma Universidade Federal de grande porte, autônoma, com muitos cursos de graduação bem-conceituados nos rankings, além de cursos de especialização, mestrados e doutorados, atingindo o número de mais de 3.000 (três mil) alunos.

Referente às implicações do ENADE na gestão dos cursos, os gestores demonstraram estar conscientes da importância do exame na produção dos resultados e comprometidos em tomar providências no sentido de atribuir responsabilidades aos coordenadores e discentes, visando melhorar o desempenho e ampliar a visibilidade dos cursos. Neste caso, os resultados obtidos no ENADE são, claramente, usados como forma de ranqueamento, em que os cursos com melhores desempenhos são amplamente divulgados para atrair novos alunos, atribuindo à educação superior um caráter de mercadoria, distanciando-a de sua função voltada ao cultivo do saber científico e ao exercício criativo da crítica (BARATA-MOURA, 2004).

[...] O ENADE é o atacante de um time, você ouve sempre "a nota da IES no ENADE é...", ou seja, um marketing para as instituições. (CF)

[...] O ENADE fica muito claro para o estudante. Ele sabe o que é e o quanto isso é importante para a IES. (CF)

[...] O ENADE está ligado diretamente à Diretoria de Graduação e toda sua estrutura é discutida e alicerçada nesta Diretoria com uma proximidade e acompanhamento direto dos coordenadores de curso. (GF)

[...] O coordenador de curso é responsável pelo ENADE no âmbito do curso. (GF)

[...] O ENADE tem um peso muito grande dentro da avaliação institucional e os alunos não têm qualquer responsabilidade com o ENADE. (CP)

[...] O estudante deve ser motivado e conscientizado da real função do ENADE. (CP)

[...] A IES usa estratégias junto à CPA para a realização do ENADE, como aulas e provas focadas no ENADE. (CP)

[...] Os resultados alcançados no ENADE e nas avaliações são avaliados pela CPA e pela própria gestão da IES buscando saná-los. (CP)

[...] O ENADE é um instrumento válido, porém deve ser realizado de forma correta. Deveria ter a responsabilização dos estudantes, pois sem isso, o mesmo não tem compromisso com o processo de avaliação da IES. (GP)

As entrevistas e questionários demonstraram que todos os segmentos pesquisados (docentes, discentes e gestores) têm conhecimento do ENADE. No entanto, dos 25 estudantes da IESF que responderam ao questionário, apenas oito afirmaram ser preparados para realizar o exame. Com relação aos docentes, apenas um docente considerou que o estudante é preparado 
para o ENADE e quatro assinalaram não haver qualquer tipo de preparação. Na IESP as respostas divergiram, significativamente, da instituição pública. Dos 25 estudantes que responderam os questionários, 17 afirmaram ser preparados para realizar o exame. Com relação aos docentes, três afirmaram que os estudantes são preparados para o exame.

Ao serem questionados se consideram o ENADE importante, 15 estudantes da IESF assinalaram "sim" e 10 assinalaram "não". Ao perguntarmos a estes mesmos estudantes se eles se consideravam responsáveis pelos resultados alcançados no ENADE, oito estudantes apontaram que "sim" e 17 estudantes assinalaram "não". Dos docentes respondentes, três docentes consideraram o ENADE fator importante para a avaliação, mas apenas dois docentes se consideraram responsáveis pelos resultados alcançados pela IES na última avaliação.

Na IESP, 21 estudantes consideraram o ENADE importante e 13 afirmaram sentir-se responsáveis pelos resultados alcançados no exame. Com relação aos docentes da IESP, todos consideram o ENADE importante para a avaliação da IES e três afirmaram sentir-se responsáveis pelos resultados alcançados pela IES na última avaliação.

As respostas indicaram que os gestores das duas instituições pesquisadas atribuem importância ao ENADE, no entanto, apenas os gestores da instituição privada confirmaram a adoção de medidas mais pontuais, como o treinamento dos alunos por meio de "aulas e provas focadas no ENADE". Com relação aos alunos e docentes, as respostas evidenciaram o forte impacto das medidas de gestão na produção de significados referentes ao exame nacional. Enquanto que, na IESP, mais de $80 \%$ dos alunos respondentes consideraram o ENADE importante e mais de $50 \%$ disseram sentir-se responsáveis pela produção do conceito atribuído pelo exame que avalia a qualidade do curso, na instituição pública $60 \%$ dos alunos consideraram o ENADE importante e 32\% disseram sentir-se responsáveis pelos resultados. Observamos, portanto que, no curso da IESP, o impacto do ENADE foi significativamente maior, resultando em treinamento dos alunos para as provas, confirmado por três docentes dos cinco respondentes, e reforço da atuação da CPA e da coordenação pedagógica na comunidade acadêmica, conforme descrito nos relatórios e relatado nas entrevistas. Na IESF, embora o exame tenha sido considerado importante, seus efeitos na organização do trabalho pedagógico se mostraram consideravelmente menores, sendo praticamente nula a ocorrência de treinamentos e ações mais pontuais voltadas, estritamente, à produção de resultados. 
FERNANDES, Cristiane; OLIVEIRA, Maria Eliza Nogueira; BORGES, Regilson Maciel. Implicações do Sinaes na gestão da educação superior: análise micropolítica.

Com relação às influências dos resultados da avaliação institucional na gestão das instituições de ensino superior pesquisadas, os entrevistados apresentaram as seguintes considerações:

[...] Acredito que o impacto dos resultados é direto e forte na gestão do curso, pois nos é cobrado o acompanhamento dos parâmetros estabelecidos pelo MEC para propor melhorias, reestruturações no projeto pedagógico, estrutura física e corpo docente. (CF)

[...] A gestão tem como desafio correr atrás de investimentos e de manter os resultados bons alcançados e melhorar sempre buscando a excelência. (GF)

[...] O impacto dos resultados é muito forte na gestão do curso e, principalmente, na gestão da IES, pois a sociedade cobra resultados melhores da IES. (CP)

[...] O impacto dos resultados negativos refletiu diretamente na gestão da IES gerando uma série de transtornos. (GP)

Apesar do número de participantes da pesquisa não permitir generalizações, mas apenas apontar tendências que venham a ser confirmadas em estudos posteriores, as entrevistas reafirmam o viés regulador, sistematizado em diretrizes, que altera o padrão de tomada de decisão e de gestão no contexto das IES. No caso da IESF, o desafio dos gestores concentra-se mais na manutenção dos resultados do que na sua produção. A confirmação do diretor da IESF de que uma de suas funções consiste em "correr atrás de investimentos" reforça a mudança de concepção a respeito do caráter público atribuído às instituições mantidas pelo Estado. A revisão desta concepção passa pela consideração de que o público não necessariamente está relacionado ao que é mantido com recursos públicos, mas, antes, àquilo que é de interesse de toda a sociedade, portanto, aberto a interferências de outras instituições, incluindo empresas e organizações não-governamentais. Este aspecto é relevante na medida em que, num contexto de redução significativa de recursos financeiros destinados pelo Estado às IES públicas, seus gestores são cada vez mais incentivados a buscar recursos em outras esferas, por meio de parcerias de diversas ordens. A entrevista do gestor revela um movimento que não se situa mais no campo das proposições dos organismos internacionais, mas da ação, cujos efeitos, certamente, necessitarão ser investigados por meio de novas pesquisas.

Os dados apresentados neste estudo nos mostram que o impacto do SINAES na instituição de ensino superior privada, especialmente no âmbito da gestão - que elegemos como categoria central na pesquisa -, tende a ser consideravelmente maior do que na instituição pública, embora 
FERNANDES, Cristiane; OLIVEIRA, Maria Eliza Nogueira; BORGES, Regilson Maciel. Implicações do Sinaes na gestão da educação superior: análise micropolítica.

os gestores das duas IES tenham revelado sofrer “cobranças" para a produção ou manutenção de resultados satisfatórios nas avaliações externas.

O modelo de avaliação institucional adotado pelo SINAES tem contribuído, portanto, para o fortalecimento da cultura gerencialista nas IES onde a política de produção de resultados acaba se sobrepondo à política de avaliação firmada em pressupostos formativos. Neste caso, a avaliação como mecanismo indutor da qualidade tem utilizado os indicadores oriundos do ENADE como instrumentos de adaptação ao instituído como parte de um sistema de controle burocrático cada vez mais rígido que, num futuro próximo, pode vir a desestabilizar as relações democráticas construídas historicamente e consolidadas nas universidades públicas brasileiras, abrindo espaço para um modelo de administração cada vez mais próximo dos modelos adotados nas empresas capitalistas. Para concluir, reiteramos nossas considerações com esta importante constatação dos pesquisadores ingleses Sharon Gewitz e Stephen Ball a respeito dos novos princípios que vêm sendo adotados na gestão educacional no contexto das políticas avaliativas em curso:

Para o novo gerente da educação, uma boa administração envolve implementação tranquila e eficiente de objetivos situados fora da escola, dentro dos limites também estabelecidos fora da escola. Não é papel do novo gerente questionar ou criticar esses objetivos e limites. O discurso do novo Gerencialismo na educação enfatiza os propósitos instrumentais de escolarização - aumentar os padrões e desempenhos conforme mensurados pela avaliação dos resultados, nível de frequência e destino dos egressos - e está frequentemente articulado a um vocabulário da empresa, excelência, qualidade e eficiência (GEWIRTZ; BALL, 2011, p. 193).

\section{Considerações finais}

Conforme indicamos na parte introdutória deste artigo, adotamos nessa pesquisa uma óptica micropolítica, com o objetivo de compreender os processos de singularização no próprio nível em que elas emergem (GUATTARI; ROLNIK, 2013, p. 152). Consideramos, em nossa análise, a maneira como a realidade foi apreendida pelos sujeitos dos cursos analisados e os aspectos envolvidos em sua construção. Interessados em compreender como os sujeitos processam, ressignificam e (re)produzem as políticas delineadas no âmbito dos governos - neste caso, as políticas de avaliação - coletamos um conjunto de dados que confirmaram a possibilidade desta política se converter em um dispositivo voltado à captura de desejos, (re)produzindo ações que contribuem com a manutenção dos sistemas instituídos. Ao mesmo 
tempo, observamos que, especialmente na IES pública, onde os processos de participação coletiva e o exercício da autonomia são mais expressivos, existe uma tendência em se atribuir menor relevância às estratégias de produção de resultados nas avaliações, embora as entrevistas realizadas com os gestores indiquem adesão progressiva aos mecanismos de controle devido à espetacularização feita em torno dos resultados das avaliações que acabam por ampliar a pressão social para a manutenção dos cursos nas posições mais elevadas nos rankings nacionais.

$\mathrm{Na}$ IESP, as estratégias de treinamento e conscientização da comunidade acadêmica a respeito do ENADE são mais efetivas, embora nem sempre sejam suficientes para produzir o resultado esperado, permitindo-nos considerar que há outros elementos implicados na melhoria do desempenho dos alunos nas avaliações externas que se sobrepõem aos mecanismos de responsabilização coletiva amplamente adotados pelos gestores das empresas privadas.

Os dados ampliaram a evidência de que, embora as instituições pesquisadas tenham resguardadas, constitucionalmente, a sua autonomia com relação aos aspectos organizacionais e pedagógicos, diante de um sistema avaliativo cada vez mais alinhado aos pressupostos gerenciais, a busca por melhores resultados vem se convertendo em uma prática comum, um certo tipo de comportamento naturalizado que cria uma identidade que passa a ser compartilhada entre os gestores independentemente do tipo de instituição em que atuam.

Certamente, este controle não se dará sem processos micropolíticos de resistência na medida em que suas implicações venham a afetar diretamente os diferentes interesses em jogo. Resta-nos, em nossas futuras pesquisas, identificar em que medida esses processos serão capazes de abalar as estruturas deste sistema, desbloqueando os processos que impedem as necessárias transformações no campo subjetivo que darão vasão a novas configurações nas práticas organizacionais que escapem ao modelo gerencial amplamente reproduzido nas Instituições de Ensino Superior. As novas pesquisas deverão ainda se atentar à identificação e análise de novos dispositivos, cada vez mais sofisticados, que vêm sendo desenvolvidos e aperfeiçoados para capturar as intenções e (re)programá-las no sentido de assegurar a conservação/reprodução da ordem capitalística.

\section{Referências}

ALONSO, Myrtes. O papel do diretor na administração escolar. Rio de Janeiro: EDUC, 1976. 
FERNANDES, Cristiane; OLIVEIRA, Maria Eliza Nogueira; BORGES, Regilson Maciel. Implicações do Sinaes na gestão da educação superior: análise micropolítica.

BARATA-MOURA, José. Educação superior: direito ou mercadoria? Avaliação: Revista da Avaliação da Educação Superior, Campinas, Sorocaba, v. 9, n. 2, p. 31-36, jun. 2004. Disponível em: http://periodicos.uniso.br/ojs/index.php/avaliacao/article/view/1266. Acesso em: 9 abr. 2018.

BAREMBLITT, Gregório F. Compêndio de análise institucional e outras correntes: teoria e prática. 5. ed. Belo Horizonte: Instituto Felix Guattari, 2002.

BENELLI, Silvio José. Cartografia das instituições de assistência social a crianças e adolescentes num município de médio porte do interior do Estado de São Paulo. 2010. 244 f. Relatório (Pesquisa de Pós-Doutorado) - Programa de Pós-Graduação em Psicologia, Universidade Estadual Paulista, Assis, 2010.

BRASIL. Lei no 10.861, de 14 de abril de 2004. Institui o Sistema Nacional de Avaliação da Educação Superior - SINAES e dá outras providências. Brasília: Casa Civil, 2004. Disponível em: http://www.planalto.gov.br/ccivil_03/_ato2004-2006/2004/lei/110.861.htm. Acesso em: 9 abr. 2018.

BRASIL. Lei n 9.394, de 20 de dezembro de 1996. Estabelece as diretrizes e bases da educação nacional. Brasília: Ministério da Educação, 1996. Disponível em: http://www.planalto.gov.br/ccivil_03/Leis/L9394.htm. Acesso em: 9 abr. 2018.

BROOKE, Nigel; CUNHA, Maria Amália de A. Avaliação externa como instrumento da gestão educacional nos estados. Estudos e Pesquisas Educacionais, São Paulo, n. 2. p. 17-79, nov. 2011.

DELEUZE; Gilles; GUATTARI, Félix. Mil Platôs: capitalismo e esquizofrenia. 2. ed. Rio de Janeiro: Editora 34, 2012. v. 3.

DIAS SOBRINHO, José. Avaliação e transformações da educação superior brasileira (1995-2009): do provão ao SINAES. Avaliação: Revista da Avaliação da Educação Superior, Campinas, Sorocaba, v. 15, n. 1, p. 195-224, mar. 2010. Disponível em: http://www.scielo.br/scielo.php?pid=S141440772010000100011\&script=sci_abstract\&tlng=pt. Acesso em: 9 abr. 2018.

FERREIRA, Suely. Reformas na educação superior: novas regulações e a reconfiguração da universidade. Educação Unisinos, São Leopoldo, v. 19, n. 1, p. 122-131, jan./abril 2015.

FERNANDES, Cristiane. As influências do SINAES na gestão de duas instituições de ensino superior e seu desempenho no ENADE. 2017. 93 f. Dissertação (Mestrado em Educação) - Programa de PósGraduação em Educação, Universidade do Oeste Paulista, Presidente Prudente, 2017.

GADELHA, Sylvio. Desempenho, gestão, visibilidade e tecnologias como vetores estratégicos de regulação e controle de condutas na contemporaneidade. Educar em Revista, Curitiba, v. 33, n. 66, p. 113-139, out./dez. 2017.

GUATTARI, Félix; ROLNIK, Suely. Micropolítica: cartografias do desejo. 12. ed. Petrópolis: Vozes, 2013.

GEWIRTZ, Sharon; BALL, Stephen J. Do modelo de gestão do "bem-estar social" ao "novo gerencialismo": mudanças discursivas sobre gestão escolar no mercado educacional. In: BALL, Setephen J.; MAINARDES, Jefferson. (org.). Políticas educacionais: questões e dilemas. São Paulo: Cortez, 2011. p. 193-221.

HADDAD, Sérgio. (org.). Banco Mundial, OMC e FMI: o impacto nas políticas educacionais. São Paulo: Cortez, 2008.

LIMA, Licínio Carlos. A avaliação institucional como instrumento de racionalização e o retorno à escola como organização formal. Educação e Pesquisa, São Paulo, v. 41, número especial, p. 1339-1352, dez. 2015.

LIMA, Licínio Carlos. A escola como organização educativa: uma abordagem sociológica. 3. ed. São Paulo: Cortez, 2008. 
FERNANDES, Cristiane; OLIVEIRA, Maria Eliza Nogueira; BORGES, Regilson Maciel. Implicações do Sinaes na gestão da educação superior: análise micropolítica.

LOURAU, René. Análise institucional e práticas de pesquisa. Rio de Janeiro: UERJ, 1993.

MINHOTO, Maria Angélica Pedra. Políticas de avaliação da educação brasileira: limites e perspectivas. Jornal de Políticas Educacionais, Curitiba, v. 10, n. 19, p. 77-90, jan./jun. 2016.

OLIVEIRA, Maria Eliza Nogueira. Qualidade da educação escolar: discursos, práticas e representações sociais. 2015. 282 f. Tese (Doutorado em Educação) - Programa de Pós-Graduação em Educação, Universidade Estadual Paulista, Marília, 2015.

RAVITCH, Diane. Vida e morte do grande sistema escolar americano: como os testes padronizados e o modelo de marcado ameaçam a educação. Porto Alegre: Sulina, 2011.

RIBEIRO, José Querino. Ensaio de uma teoria da administração escolar. São Paulo: FFCL/USP, 1952. (Administração escolar e educação comparada; boletim 158).

SOUSA, José Vieira de. Avaliação institucional, estratégias de marketing e imagens projetadas pelas IES: que relação é essa? In: OLIVEIRA, João Ferreira de; FONSECA, Marília (orgs.). Avaliação institucional: sinais e práticas. São Paulo: Xamã, 2008. p. 77-103. 